\title{
Dietary supplementation with $\beta$-hydroxy- $\beta$-methylbutyrate calcium during the early postnatal period accelerates skeletal muscle fibre growth and maturity in intra-uterine growth-retarded and normal-birth-weight piglets
}

\author{
Haifeng Wan†, Jiatao Zhu†, Guoqi Su†, Yan Liu, Lun Hua, Liang Hu, Caimei Wu, Ruinan Zhang, \\ Pan Zhou, Yong Shen, Yan Lin, Shengyu Xu, Zhengfeng Fang, Lianqiang Che, Bin Feng and De Wu* \\ Institute of Animal Nutrition, Sichuan Agricultural University, No. 211, Huimin Road, Wenjiang District, Chengdu, Sichuan \\ 611130, People's Republic of China
}

(Submitted 30 September 2015 - Final revision received 15 January 2016 - Accepted 21 January 2016 - First published online 26 February 2016)

\section{Abstract}

Intra-uterine growth restriction (IUGR) impairs postnatal growth and skeletal muscle development in neonatal infants. This study evaluated whether dietary $\beta$-hydroxy- $\beta$-methylbutyrate $\mathrm{Ca}(\mathrm{HMB}-\mathrm{Ca})$ supplementation during the early postnatal period could improve muscle growth in IUGR neonates using piglets as a model. A total of twelve pairs of IUGR and normal-birth-weight (NBW) male piglets with average initial weights (1.85 (SEM 0.36) and 2.51 (SEM 0.39$) \mathrm{kg}$, respectively) were randomly allotted to groups that received milk-based diets (CON) or milkbased diets supplemented with $800 \mathrm{mg} / \mathrm{kg}$ HMB-Ca (HMB) during days 7-28 after birth. Blood and longissimus dorsi (LD) samples were collected and analysed for plasma amino acid content, fibre morphology and the expression of genes related to muscle development. The results indicate that, regardless of diet, IUGR piglets had a significantly decreased average daily weight gain (ADG) compared with that of NBW piglets $(P<0 \cdot 05)$. However, IUGR piglets fed HMB-Ca had a net weight and ADG similar to that of NBW piglets fed the CON diet. Irrespective of body weight (BW), HMB-Ca supplementation markedly increased the type II fibre cross-sectional area and the mRNA expression of mammalian target of rapamycin $(m T O R)$, insulin-like growth factor-1 and myosin heavy-chain isoform $I I b$ in the LD of piglets $(P<0.05)$. Moreover, there was a significant interaction between the effects of BW and HMB on $m T O R$ expression in the LD $(P<0 \cdot 05)$. In conclusion, HMB-Ca supplementation during the early postnatal period could improve skeletal muscle growth and maturity by accelerating fast-twitch glycolytic fibre development in piglets.

Key words: $\boldsymbol{\beta}$-Hydroxy- $\boldsymbol{\beta}$-methylbutyrate calcium: Growth and development: Piglets: Skeletal muscle fibre

It has been well demonstrated that approximately $10 \%$ of human neonates might suffer from intra-uterine growth restriction (IUGR) at birth and remain small throughout their lives, which results in serious effects on their health ${ }^{(1,2)}$. Furthermore, there is some evidence that IUGR severely impairs the growth and development of skeletal muscle in neonates ${ }^{(3,4)}$ and reduces the number of secondary and total muscle fibre, potentially resulting in decreased muscle mass and delayed skeletal muscle maturity ${ }^{(5,6)}$. More importantly, neonates with IUGR have altered muscle energy metabolism and function, which have been associated with a decreased ability for glucose uptake by muscle tissue and the development of insulin resistance as adults ${ }^{(7,8)}$. Research has documented that the growth and protein turnover of infants are higher during the neonatal period than that at any other period of life ${ }^{(9)}$, and a defect in normal muscle development during the early postnatal period can influence later growth and health, as well as muscle contractile properties and metabolic maturation ${ }^{(10)}$. Therefore, the improvement of skeletal muscle development in IUGR piglets is of interest.

In recent years, considerable effort has been focused on improving the postnatal growth of IUGR neonates via nutritional regulation. Growing evidence indicates that both leucine and its metabolite ( $\beta$-hydroxy- $\beta$-methylbutyrate, HMB) stimulate protein synthesis in skeletal muscle through the activation of the mammalian target of rapamycin (mTOR) signalling pathway in piglets and rats ${ }^{(11,12)}$. In addition, studies have indicated that neonatal pigs infused with HMB (free acid) have higher skeletal muscle protein synthesis ${ }^{(13)}$. In addition, Moore et $a l^{(14)}$ reported that early post-hatch poultry fed with $\mathrm{HMB}$ had better muscle development via an increase in the mitotic activity of myogenic

Abbreviations: BW, body weight; CK, creatine kinase; CON, control; CSA, cross-sectional area; HMB, $\beta$-hydroxy- $\beta$-methylbutyrate; HMB-Ca, $\beta$-hydroxy$\beta$-methylbutyrate calcium; IGF-1, insulin-like growth factor-1; IUGR, intra-uterine growth restriction; LD, longissimus dorsi; LDH, lactate dehydrogenase; NBW, normal birth weight; $M R F-4$, muscle regulatory factor $4 ; m T O R$, mammalian target of rapamycin; MyHC, myosin heavy-chain.

* Corresponding author: Professor D. Wu, fax +86 2886291256; email sow_nutrition@sina.com

$\dagger$ These authors contributed equally to this work. 
satellite cells. Moreover, HMB supplementation stimulated growth hormone-insulin-like growth factor (IGF) axis activity and decreased the rate of protein breakdown in a rodent model $^{(15,16)}$. However, there are only limited data on the effects of dietary exposure to HMB on skeletal muscle growth and maturity and amino acid metabolism in IUGR neonates during the early postnatal period. Sufficient skeletal muscle growth is essential for lasting metabolic health. Because of the structural and physiological similarities in skeletal muscle between pigs and humans, this study used piglets to assess the effects of dietary supplementation with $\beta$-hydroxy- $\beta$-methylbutyrate Ca (HMB-Ca) on skeletal muscle growth, the plasma amino acid profile, and the expression of muscle growth and development-related genes of IUGR neonates during the early postnatal period.

\section{Methods}

\section{Animal care and experimental design}

All procedures were in accordance with the guidelines set by the Animal Care and Use Committee of the Animal Nutrition Institute, Sichuan Agricultural University. The Ca salt (monohydrate) of HMB (purity 93\%) was purchased from Jiangyin Sanyi Chemical Co. Ltd. Neonatal piglets from parities 2 and 3 of thirty sows were selected for this study. At day 7 after birth, a total of twelve pairs of IUGR (body weight (BW) 1.85 (SEM 0.36) kg) and normal-birth-weight (NBW) (BW 2.51 (SEM 0.39) kg) male piglets were weaned and assigned, according to BW, to groups fed the basal diets supplemented with 0 or $0.08 \%$ HMB-Ca. There were four treatment groups (birth weight/diet): IUGR/control (CON), IUGR/HMB, NBW/CON and NBW/HMB (six per group). All piglets were fed liquid diets every $3 \mathrm{~h}$ by bottle feeding from 7 and $28 \mathrm{~d}$ of age. All piglets were housed individually in metabolism cages $(0.8 \times 0.7 \times 0.4 \mathrm{~m})$ at an ambient temperature of $30^{\circ} \mathrm{C}$ in an environmentally controlled room and had free access to water.

\section{Formula milk}

The experimental diets used for the present study were prepared by adding $800 \mathrm{mg} / \mathrm{kg}$ HMB-Ca to the basal diet (Table 1 ). The basic milk replacement powder was formulated according to previous studies ${ }^{(17)}$. The dosage of supplemented HMB-Ca $(800 \mathrm{mg} / \mathrm{kg}$ ) was chosen according to previous studies on 7-d-old piglets ${ }^{(13)}$. The diets were prepared by mixing $1 \mathrm{~kg}$ of milk replacement powder (DM, 87.5\%) with $4000 \mathrm{ml}$ of water and were given to piglets via bottle feeding seven times per $24 \mathrm{~h}$. The formula milk intake of the piglets was recorded daily. The average daily DM intake (ADMI) was calculated by multiplying the average daily intake of formula milk by its corresponding DM content. Formula milk intake was calculated as the difference between the offered amounts and the amount refused.

\section{Blood and tissue samples collection}

At day 29 after birth, blood samples $(5 \mathrm{ml})$ were collected from the jugular vein after an overnight fast and immediately centrifuged for $10 \mathrm{~min}$ at $3500 \mathrm{~g}$. The supernatants were stored at $-20^{\circ} \mathrm{C}$ until analysis. All piglets were euthanised with an overdose
Table 1. Composition and nutrient content of the basal diet (87.5\% DM basis)*

\begin{tabular}{|c|c|}
\hline Ingredients & $\%$ \\
\hline Whole-milk powder (24\% CP) & 58.00 \\
\hline Whey protein concentrate (34\% CP) & $25 \cdot 00$ \\
\hline Casein & $2 \cdot 00$ \\
\hline Coconut oil & $10 \cdot 00$ \\
\hline Glucose & $2 \cdot 15$ \\
\hline Dicalcium phosphate (18\% P) & 0.18 \\
\hline Choline chloride (50\%) & $0 \cdot 10$ \\
\hline Vitamin mixture & $0 \cdot 10$ \\
\hline Mineral premix $\ddagger$ & 0.50 \\
\hline L-Lys.HCl (78.5\%) & 0.60 \\
\hline DL-Met $(98.5 \%)$ & $0 \cdot 15$ \\
\hline L-Thr (98\%) & $0 \cdot 17$ \\
\hline L-Trp $(98 \%)$ & $0 \cdot 10$ \\
\hline L-Arg $(98.5 \%)$ & $0 \cdot 15$ \\
\hline L-Ala (99.0\%) & 0.80 \\
\hline Total & $100 \cdot 00$ \\
\hline \multicolumn{2}{|l|}{ Nutrient content } \\
\hline Digestible energy (MJ/kg) & $17 \cdot 74$ \\
\hline $\mathrm{CP}(\%)$ & $25 \cdot 03$ \\
\hline $\mathrm{Ca}(\%)$ & 0.88 \\
\hline Total P (\%) & 0.62 \\
\hline Available P (\%) & 0.62 \\
\hline Digestible Lys (\%) & 2.07 \\
\hline Digestible Met (\%) & 0.88 \\
\hline Digestible Leu (\%) & $2 \cdot 40$ \\
\hline Digestible Arg (\%) & 0.86 \\
\hline
\end{tabular}

$\mathrm{CP}$, crude protein; HMB-Ca, $\beta$-hydroxy- $\beta$-methylbutyrate $\mathrm{Ca}$.

* The $\beta$-hydroxy- $\beta$-methylbutyrate diet was prepared by supplementing the basal diet with $800 \mathrm{mg} / \mathrm{kg} \mathrm{HMB}-\mathrm{Ca}$ and removing the same amount of dicalcium phosphate. † Vitamin premix provided per kg of powder diet: vitamin A, $0.94 \mathrm{mg}$; vitamin $D_{3}$, $0.01 \mathrm{mg}$; vitamin $\mathrm{E}, 20 \mathrm{mg}$; vitamin $\mathrm{K}_{3}, 1 \mathrm{mg}$; vitamin $\mathrm{B}_{12}, 0.04 \mathrm{mg}$; riboflavin, $5 \mathrm{mg}$; niacin, $20 \mathrm{mg}$; pantothenic acid, $15 \mathrm{mg}$; folic acid, $1.5 \mathrm{mg}$; thiamin, $1.5 \mathrm{mg}$; pyridoxine, $2 \mathrm{mg}$; biotin, $0.1 \mathrm{mg}$.

‡ Mineral premix provided per kg of powder diet: Zn, $90 \mathrm{mg}$; Mn, $40 \mathrm{mg} ; \mathrm{Fe}, 90 \mathrm{mg}$; $\mathrm{Cu}, 6.0 \mathrm{mg} ; \mathrm{I}, 0.2 \mathrm{mg}$; Se, $0.3 \mathrm{mg}$.

of anaesthesia according to the method described by Han et $a l .{ }^{(17)}$. After death, the abdomen was opened, and the entire intestine was rapidly removed. Then longissimus dorsi (LD) muscle samples from the left half of the carcass were collected at the level of the twelfth/thirteenth ribs and cooled using liquid $\mathrm{N}_{2}$ and stored at $-80^{\circ} \mathrm{C}$ until subsequent analyses. For body composition analysis of the piglets, all internal organs were weighted, and the right half of the carcass was dissected into primary cuts, such as the loin, neck and ham, which were further manually separated into muscle tissue, subcutaneous adipose tissue, skin and bones after cooling overnight at $4^{\circ} \mathrm{C}$, as described previously by Rehfeldt $e t a l .{ }^{(18)}$. The muscle tissue of the piglets consisted of the total amount of skeletal muscle and intramuscular fat, and the whole superficial fat layer consisted of the subcutaneous fat. Muscle samples for histochemical analysis were collected from $\mathrm{LD}$ on the right side of the carcass and cut into $2-\mathrm{cm}^{3}$ pieces $(1.0 \times 1.0 \times 2.0 \mathrm{~cm}$, parallel to the muscle fibres $)$.

\section{Biochemical analyses}

The DNA of muscle samples was extracted using a QIAamp ${ }^{\circledR}$ DNA Mini Kit (Qiagen) according to the manufacturer's instructions, and DNA quantification was performed using a NanoVue Plus spectrophotometer (GE Life Sciences). The protein concentration and the creatine kinase (CK) and lactate 
dehydrogenase (LDH) activities of muscle samples were determined using commercial kits (Nanjing Jiancheng Bioengineering Institute) according to the instruction manuals. Briefly, frozen muscle samples (approximately $50 \mathrm{mg}$ ) were homogenised in $450 \mu \mathrm{l}$ of $0.9 \%$ saline and then centrifuged at $3500 \mathrm{~g}$ for $10 \mathrm{~min}$ at $4^{\circ} \mathrm{C}$. The protein content in the muscle supernatant was determined with the Coomassie Brilliant Blue dyeing method using bovine serum albumin as the standard and expressed as milligram per gram. CK activity was measured in the supernatants of the muscle homogenates at 1:10 and 1:5 dilution. The optical density in microplate assays was measured at 595 and $660 \mathrm{~nm}$ for protein concentration and CK activity, respectively, using a biochemical analyser (Multiskan Spectrum; Thermo Scientific).The plasma insulin concentration was analysed using a porcine insulin RIA kit (Tianjin Jiuding Medical Biological Engineering Co. Ltd).

Muscle tissue samples were measured for HMB content by a modification of the plasma and milk sample analysis method previously described by Deshpande et $a l^{(19)}$ and Ehling \& Reddy ${ }^{(20)}$. Briefly, acidified muscle tissue homogenates were extracted with methyl-t-butyl ether for $2 \mathrm{~h}$, and $\alpha$-hydroxy- $\alpha$ methylbutyric acid (Sigma H40009; Sigma-Aldrich) was used as an internal standard. The extracting solution was centrifuged at $12000 \mathrm{~g}$ and $4^{\circ} \mathrm{C}$ for $5 \mathrm{~min}$. Then, the supernatant was transferred to a clean test tube and evaporated to dryness by $\mathrm{N}$ flushing at $40^{\circ} \mathrm{C}$. After drying, $4 \mathrm{ml}$ of $0 \cdot 10 \mathrm{M}-\mathrm{HCl}$ in $90: 10(\mathrm{v} / \mathrm{v})$ water-acetonitrile was added to the same test tube. After a brief vortex mixing, the mixture was passed through an OASIS ${ }^{\circledR}$ MCX cartridge $(60 \mathrm{mg}$ ) (Waters) and the eluate was collected. The HMB content was analysed via HPLC with MS (Agilent).

The plasma free amino acid content was determined according to the method described by Li et al. ${ }^{(21)}$. Briefly, $300 \mu \mathrm{l}$ of the plasma sample and $900 \mu \mathrm{l}$ of $10 \%$ sulphosalicylic acid were mixed and centrifuged at $12000 \mathrm{~g}$ and $4^{\circ} \mathrm{C}$ for $15 \mathrm{~min}$. Then, the supernatant was filtered through a $0 \cdot 22-\mu \mathrm{m}$-pore-size PTFE syringe filter (Millipore) into a 2-ml auto-sampler vial and analysed for amino acid content by an automatic amino acid analyzer (Hitachi). Amino acid standard solutions type B and AN-II (Wako Pure Chemical Industries Ltd) were used for calibration.

\section{Histochemistry and microscopy}

The LD samples were mounted on a cryostat chuck with a few drops of tissue-freezing medium, and then serial 10- $\mu \mathrm{m}$ sections were cut at $-20^{\circ} \mathrm{C}$. Sections were stained with a typical ATPase stain following alkalinisation $(\mathrm{pH}=9 \cdot 40)$ and acidification ( $\mathrm{pH}=4 \cdot 20)$ to evaluate muscle morphology using a modification of the method of Guth \& Samaha ${ }^{(22)}$. All sections were photographed using a digital microscope (Nikon), and the muscle fibres were counted in five randomly selected fields of known size (1.01 mm², 200-300 fibres). The muscle fibre crosssectional area (CSA) in the total area analysed was measured with Image-Pro Plus version 6.0 software (Media Cybernetics).

\section{Total RNA extraction and real-time RT-PCR}

The genes detected in the muscle samples included myosin heavy-chain (MyHC) isoform (I, IIa, IIx and IIb), muscle regulatory factor $4(M R F-4)$, myogenin $(M y o G), I G F-1$, mTOR, myostatin $(M S T N)$ and $\beta$-actin. The information about the primer pairs for the selected genes is summarised in Table 2 . Total RNA was extracted from the frozen samples using TRIzol (Invitrogen) according to the manufacturer's protocol. Real-time quantitative PCR (qPCR) analysis was performed using the SYBR Green method, and the target genes were quantified using CFX manager version 1.1 software (Bio-Rad Laboratories). A commercial RT kit (TaKaRa) was used for the synthesis of complementary DNA (cDNA). The qRT-PCR reaction contained $5 \mu \mathrm{l}$ of SYBR Green supermix (TaKaRa), $1 \mu \mathrm{l}$ of cDNA, $0.5 \mu \mathrm{l}$ of each gene-specific primer and $3 \mu$ of double-distilled $\mathrm{H}_{2} \mathrm{O}$. The following thermal cycling conditions were used: denaturation at $95^{\circ} \mathrm{C}$ for $15 \mathrm{~s}$, followed by forty cycles of denaturation at $95^{\circ} \mathrm{C}$ for $5 \mathrm{~s}$ and annealing at $61.5^{\circ} \mathrm{C}$ for $30 \mathrm{~s}$. To confirm the specificity of each product, a melting curve analysis $\left(50-95^{\circ} \mathrm{C}\right.$ with a heating rate of $0 \cdot 1{ }^{\circ} \mathrm{C} / \mathrm{s}$ and continuous fluorescence measurement) was performed, and the size of the products was determined by agarose gel electrophoresis. The qPCR analysis of each sample was repeated three times. The relative mRNA abundances of the detected genes were calculated using the $2^{-\Delta \Delta C_{T}} \operatorname{method}^{(21)}$.

\section{Tissue protein extraction and Western blot analysis}

The frozen LD samples were lysed and the protein concentration was determined using a protein assay kit according to the manufacturer's instructions. Western blot analysis of fast-MyHC content using the anti-fast myosin skeletal heavy chain antibody (ab91506, diluted 1:5000; Abcam) was carried out as described previously ${ }^{(23)}$. The relative expression of the target protein was normalised to that of glyceraldehyde-3-phosphate dehydrogenase $(G A P D H)$ (Bio-Rich 042, BMSX, diluted 1:20000; Beijing BMSX Technology Co. Ltd), which was used as the internal standard. The band density of fast-MyHC was

Table 2. Primer sequences of the target genes

\begin{tabular}{|c|c|c|}
\hline Target genes & Primer sequence $\left(5^{\prime}-3^{\prime}\right)$ & GenBank no. \\
\hline $\mathrm{MyHC-I}$ & $\begin{array}{l}\text { F: GTTTGCCAACTATGCTGGGG } \\
\text { R: TGTGCAGAGCTGACACAGTC }\end{array}$ & NM_213855.1 \\
\hline MyHC-IIa & $\begin{array}{l}\text { F: CTCTGAGTTCAGCAGCCATGA } \\
\text { R: GATGTCTTGGCATCAAAGGGC }\end{array}$ & AB025260 \\
\hline$M y H C-I / x$ & $\begin{array}{l}\text { F: TTGACTGGGCTGCCATCAAT } \\
\text { R: GCCTCAATGCGCTCCTTTTC }\end{array}$ & AB025262 \\
\hline$M y H C-I l b$ & $\begin{array}{l}\text { F: GAGGTACATCTAGTGCCCT } \\
\text { R: GCAGCCTCCCCAAAAATAGC }\end{array}$ & AB025261 \\
\hline$M R F-4$ & $\begin{array}{l}\text { F: CCTTCGGTGCCTTTCTTCCAT } \\
\text { R: GAGTTATTTCTCCCCCACTTCC }\end{array}$ & NM_001244672.1 \\
\hline MyoG & $\begin{array}{l}\text { F: GACATCCCCCTACTTCTACCA } \\
\text { R: TCCCCAGCCCCTTATCTTC }\end{array}$ & NM_001012406.1 \\
\hline mTOR & $\begin{array}{l}\text { F: CATTGGAGATGGTTTGGTGA } \\
\text { R: ATGGGATGTGGCTTGTTTGA }\end{array}$ & XM_003127584.3 \\
\hline$I G F-1$ & $\begin{array}{l}\text { F: CACAGACGGGCATCGTGGAT } \\
\text { R: ACTTGGCAGGCTTGAGGGGT }\end{array}$ & FJ914498.1 \\
\hline MSTN & $\begin{array}{l}\text { F: TTTACCTGTTTATGCTGATTGTTG } \\
\text { R: TTTGCTAATGTTAGGAGCTGTTTC }\end{array}$ & AY448008.2 \\
\hline$\beta$-Actin & $\begin{array}{l}\text { F: CCAGCACGATGAAGATCAAGA } \\
\text { R: AATGCAACTAACAGTCCGCCTA }\end{array}$ & AY550069.1 \\
\hline
\end{tabular}

MyHC, myosin heavy chain; $F$, forward; $R$, reverse; $M R F-4$, muscle regulatory factor 4; MyoG, myogenin; mTOR, mammalian target of rapamycin; IGF-1, insulin-like growth factor-1; MSTN, myostatin. 
normalised to that of GAPDH, and fast-MyHC protein content was presented as the fold change relative to that of the NBW piglets in the control group.

\section{Statistical analysis}

All data were checked for a normal distribution and homogeneous variance. In addition, all data were analysed using the Proc MIXED procedure (SAS Institute Inc.) according to the following statistical model $Y_{i j k}=\mu+\alpha_{i}+\beta_{j}+(\alpha \beta)_{i j}+\varepsilon_{i j k}$ $\left(i=1,2 ; j=1,2 ; k=1,2, \ldots, n_{i j}\right)$, where $Y_{i j k}$ is the response variable, $\mu$ the overall mean, $\alpha_{i}$ the effect of BW ( $i=$ IUGR or $\mathrm{NBW}), \beta_{j}$ the effect of HMB ( $j=\mathrm{CON}$ or HMB), $(\alpha \beta)_{i j}$ the interaction between $\mathrm{BW}$ and $\mathrm{HMB}$ and $\varepsilon_{i j k}$ represents the random error, which was assumed to be $N(0, \sigma 2)$. Piglets were considered as the experimental unit. Differences between groups were analysed using the general linear model procedure followed by Duncan's test. The results for muscle fibre CSA and fast-MyHC protein expression are presented as the mean values with their standard errors, and other data in tables are presented as the mean and pooled standard errors. Probability values $<0.05$ were considered statistically significant, and values between 0.05 and 0.1 were considered to indicate trends.

\section{Results}

\section{Performance and body composition of piglets}

The results of piglet performance and body composition are presented in Tables 3 and 4 . At the onset of the experiment (day 7 after birth), no differences were observed in the BW of IUGR and NBW piglets between the two dietary treatments, and the final BW and BW gain of the IUGR piglets were both lower than those of their NBW counterparts $(-36 \%, P<0.01)$.

Table 3. Effect of dietary $\beta$-hydroxy- $\beta$-methylbutyrate (HMB) calcium supplementation on the growth performance of intra-uterine growth restriction (IUGR) and normal-birth-weight (NBW) piglets

(Mean values with their standard errors)

\begin{tabular}{|c|c|c|c|c|c|c|c|c|}
\hline \multirow[b]{2}{*}{ Parameters } & \multicolumn{2}{|c|}{ CON } & \multicolumn{2}{|c|}{ HMB } & \multirow[b]{2}{*}{ SEM } & \multicolumn{3}{|c|}{$P$} \\
\hline & IUGR & NBW & IUGR & NBW & & BW & $\mathrm{HMB}$ & $\mathrm{BW} \times \mathrm{HMB}$ \\
\hline Initial weight (kg) & $1 \cdot 84^{\mathrm{C}}$ & $2 \cdot 79^{a}$ & $1.99^{b, c}$ & $2 \cdot 44^{a, b}$ & 0.19 & 0.002 & 0.599 & 0.196 \\
\hline Final weight (kg) & $5 \cdot 80^{\mathrm{b}}$ & $8.09^{a}$ & $6 \cdot 40^{\mathrm{b}}$ & $8 \cdot 52^{\mathrm{a}}$ & 0.46 & $<0.001$ & 0.279 & 0.864 \\
\hline Net weight $(\mathrm{kg})$ & $3.96^{\mathrm{C}}$ & $5 \cdot 29^{a, b}$ & $4 \cdot 41^{b, c}$ & $6 \cdot 08^{\mathrm{a}}$ & 0.32 & $<0.001$ & 0.078 & 0.610 \\
\hline \multicolumn{9}{|l|}{ ADG $(g / d)$} \\
\hline Days 7-14 & $95^{\mathrm{b}}$ & $132^{a, b}$ & $138^{a, b}$ & $175^{\mathrm{a}}$ & 17 & 0.021 & 0.043 & 0.981 \\
\hline Days $14-21$ & $114^{\mathrm{c}}$ & $180^{\mathrm{a}, \mathrm{b}}$ & $96^{\mathrm{b}, \mathrm{c}}$ & $228^{\mathrm{a}}$ & 25 & 0.001 & 0.542 & 0.204 \\
\hline Days $21-28$ & $358^{b}$ & $438^{a, b}$ & $402^{a, b}$ & $465^{a}$ & 29 & 0.029 & 0.247 & 0.768 \\
\hline Days $7-28$ & $189^{\mathrm{c}}$ & $252^{a, b}$ & $210^{\mathrm{b}, \mathrm{c}}$ & $290^{\mathrm{a}}$ & 15 & $<0.001$ & 0.077 & 0.605 \\
\hline \multicolumn{9}{|l|}{ ADMI (g/d) } \\
\hline Days $7-14$ & $79^{b}$ & $115^{\mathrm{a}}$ & $82^{b}$ & $116^{\mathrm{a}}$ & 8 & 0.001 & 0.784 & 0.879 \\
\hline Days $14-21$ & $118^{\mathrm{b}}$ & $176^{a}$ & $102^{\mathrm{b}}$ & $196^{a}$ & 14 & $<0.001$ & 0.913 & 0.235 \\
\hline Days $21-28$ & $209^{c}$ & $264^{\mathrm{a}, \mathrm{b}}$ & $236^{b, c}$ & $292^{\mathrm{a}}$ & 16 & 0.004 & 0.105 & 0.988 \\
\hline Days $7-28$ & $135^{\mathrm{b}}$ & $185^{a}$ & $140^{\mathrm{b}}$ & $201^{a}$ & 10 & $<0.001$ & 0.318 & 0.598 \\
\hline \multicolumn{9}{|l|}{$\mathrm{FCR}^{*}$} \\
\hline Days 7-14 & 0.86 & 0.89 & 0.66 & 0.67 & 0.08 & 0.754 & 0.022 & 0.932 \\
\hline Days $14-21$ & 1.20 & 1.05 & 1.30 & 0.87 & 0.21 & 0.184 & 0.852 & 0.518 \\
\hline Days $21-28$ & 0.59 & 0.60 & 0.59 & 0.63 & 0.01 & 0.094 & 0.305 & 0.532 \\
\hline Days $7-28$ & $0.72^{a}$ & $0.74^{a}$ & $0.67^{\mathrm{b}}$ & $0.69^{a, b}$ & 0.01 & 0.188 & 0.006 & 0.664 \\
\hline
\end{tabular}

CON, control; BW, body weight; ADG, average daily weight gain; ADMI, average daily DM intake; FCR, feed conversion ratio.

a,b,c Mean values within a row with unlike superscript letters were significantly different $(P<0.05)$.

* FCR was calculated by dividing the ADMI by its corresponding ADG.

Table 4. Effects of dietary $\beta$-hydroxy- $\beta$-methylbutyrate (HMB) calcium supplementation on body composition of intra-uterine growth restriction (IUGR) and normal-birth-weight (NBW) piglets

(Mean values with their standard errors)

\begin{tabular}{|c|c|c|c|c|c|c|c|c|}
\hline \multirow[b]{2}{*}{ Parameters } & \multicolumn{2}{|c|}{ CON } & \multicolumn{2}{|c|}{ HMB } & \multirow[b]{2}{*}{ SEM } & \multicolumn{3}{|c|}{$P$} \\
\hline & IUGR & NBW & IUGR & NBW & & BW & $\mathrm{HMB}$ & $\mathrm{BW} \times \mathrm{HMB}$ \\
\hline Hot carcass weight $(\mathrm{kg})$ & $3.88^{\mathrm{b}}$ & $5 \cdot 66^{\mathrm{a}}$ & $4 \cdot 18^{b}$ & $5 \cdot 71^{\mathrm{a}}$ & 0.33 & $<0.001$ & 0.605 & 0.724 \\
\hline Internal organ (\%) & 5.52 & $5 \cdot 61$ & 5.33 & 5.46 & 0.12 & 0.374 & 0.186 & 0.857 \\
\hline Muscle tissue (\%) & $60.58^{a, b}$ & $58.84^{\mathrm{b}}$ & $62 \cdot 43^{\mathrm{a}}$ & $61.44^{\mathrm{a}, \mathrm{b}}$ & 1.00 & 0.198 & 0.044 & 0.719 \\
\hline \multicolumn{9}{|l|}{ Subcutaneous } \\
\hline Fat (\%) & 13.32 & 14.72 & 12.63 & 13.32 & 0.77 & 0.197 & 0.199 & 0.651 \\
\hline Bone (\%) & $16 \cdot 03$ & $15 \cdot 66$ & $15 \cdot 60$ & 14.86 & 0.87 & 0.538 & 0.492 & 0.838 \\
\hline Skin (\%) & 10.07 & 10.77 & 9.35 & $10 \cdot 38$ & 0.67 & 0.223 & 0.429 & 0.815 \\
\hline
\end{tabular}

CON, control; BW, body weight.

${ }^{a, b}$ Mean values within a row with unlike superscript letters were significantly different $(P<0.05)$. 
However, the IUGR piglets fed HMB-Ca milk exhibited a net weight and average daily weight gain (ADG) similar to that of the CON-fed NBW piglets. Regardless of $\mathrm{BW}$, piglets in the HMB group also showed an increased ADG $(+14 \%, P<0 \cdot 10)$ and a decreased feed conversion rate $(-7 \%, P<0.01)$ from day 7 to 28 in comparison with that of the control pigs. In addition, HMB-Ca treatment increased $(P<0.05)$ the relative ratio of skeletal muscle by 3.1 and $4.4 \%$ for the IUGR and NBW piglets, respectively, compared with that of the piglets fed the control diet.

\section{Plasma amino acid and insulin concentrations, and muscle $\beta$-hydroxy- $\beta$-methylbutyrate levels of piglets}

As shown in Table 5, irrespective of BW, piglets supplemented with HMB-Ca milk had an increased HMB concentration in their LD $(P<0 \cdot 01)$ relative to that of piglets fed CON milk. Piglets fed the HMB-Ca supplemented milk also had an elevated plasma insulin concentration $(P<0 \cdot 01)$ relative to that of their CON counterparts. In addition, in comparison with the content in the CON piglets, dietary HMB-Ca treatment increased plasma leucine and branched-chain amino acid (BCAA) content $(P<0.05)$. Similarly, plasma essential amino acid (EAA) and non-essential amino acid (NEAA) content showed increased levels $(P<0.05)$ in piglets from the HMB group relative to the levels in the CON groups, but no interaction $(P>0.05)$ between BW and HMB treatment was observed. Furthermore, the plasma urea content intra-uterine growth restriction (IUGR) and normal-birth-weight (NBW) piglets

(Mean values with their standard errors) of the IUGR piglets was lower than that of the NBW piglets $(P<0 \cdot 01)$.

\section{Biochemical and histological properties of the longissimus dorsi of piglets}

Data for CK and LDH activity, DNA and protein content, and the muscle fibre CSA of the skeletal muscle from the piglets are shown in Table 6 and Fig. 1. Regardless of BW, both the CK $(P<0.05)$ and LDH activity $(P<0.05)$ of the LD were greatly increased in piglets fed HMB-Ca milk compared with that in piglets fed CON milk. Furthermore, the mean type II fibre CSA of the LD of piglets fed HMB-Ca milk was significantly increased $(P<0.01)$ relative to that of pigs supplemented with the CON milk, and the type I fibre CSA of the LD of IUGR piglets was lower than that of NBW piglets $(P<0 \cdot 01)$.

\section{Gene expression in the longissimus dorsi of piglets}

As shown in Table 7, regardless of BW, piglets fed HMB milk had significantly higher $M y H C-I I b$ mRNA levels in the LD $(P<0.05)$ than did pigs fed CON milk. Furthermore, compared with the levels of the CON group, the mRNA levels of $I G F-1$, $m T O R$ and $M R F-4$ in the LD were up-regulated in piglets fed HMB-Ca milk $(P<0 \cdot 05)$. However, there was no significant interaction between the effects of BW and HMB treatment on the mRNA abundance of these genes in the LD, except on mTOR $(P<0.05)$.

Table 5. Effects of dietary $\beta$-hydroxy- $\beta$-methylbutyrate $(\mathrm{HMB})$ calcium supplementation on the plasma amino acid profile and muscle HMB level of

\begin{tabular}{|c|c|c|c|c|c|c|c|c|}
\hline & \multicolumn{2}{|c|}{ CON } & \multicolumn{2}{|c|}{ HMB } & \multirow[b]{2}{*}{ SEM } & \multicolumn{3}{|c|}{$P$} \\
\hline & IUGR & NBW & IUGR & NBW & & BW & HMB & $\mathrm{BW} \times \mathrm{HMB}$ \\
\hline Muscle HMB (nmol/g tissue) & $6.04^{\mathrm{b}}$ & $5 \cdot 28^{\mathrm{b}}$ & $8 \cdot 77^{\mathrm{a}}$ & $8.83^{a}$ & 0.44 & 0.434 & $<0.001$ & 0.366 \\
\hline Plasma insulin $(\mu \mathrm{U} / \mathrm{ml})$ & $7 \cdot 89^{b, c}$ & $6.53^{\mathrm{c}}$ & $10 \cdot 56^{a, b}$ & $12 \cdot 97^{a}$ & 1.00 & 0.607 & $<0.001$ & 0.077 \\
\hline Plasma urea $(\mathrm{mmol} / \mathrm{l})$ & $4 \cdot 97^{\mathrm{b}}$ & $7.52^{\mathrm{a}}$ & $5 \cdot 21^{\mathrm{b}}$ & $7 \cdot 27^{\mathrm{a}}$ & 0.39 & $<0.001$ & 0.990 & 0.540 \\
\hline \multicolumn{9}{|l|}{ Plasma amino acid $(\mathrm{nmol} / \mathrm{ml})$} \\
\hline Leu & $209^{a}$ & $156^{\mathrm{b}}$ & $224^{a}$ & $223^{a}$ & 17 & 0.126 & 0.026 & 0.141 \\
\hline BCAA & $675^{\mathrm{a}, \mathrm{b}}$ & $577^{\mathrm{b}}$ & $750^{\mathrm{a}}$ & $713^{\mathrm{a}}$ & 87 & 0.094 & 0.013 & 0.436 \\
\hline EAA & $1670^{\mathrm{a}, \mathrm{b}}$ & $1560^{\mathrm{b}}$ & $1819^{\mathrm{a}, \mathrm{b}}$ & $1909^{a}$ & 202 & 0.917 & 0.019 & 0.306 \\
\hline NEAA & $2440^{\mathrm{b}}$ & $2570^{\mathrm{b}}$ & $3512^{\mathrm{a}}$ & $3208^{\mathrm{a}}$ & 281 & 0.515 & $<0.001$ & 0.118 \\
\hline
\end{tabular}

CON, control; BW, body weight; BCAA, branched-chain amino acid; EAA, essential amino acid; NEAA, non-essential amino acid.

a,b,c Mean values within a row with unlike superscript letters were significantly different $(P<0.05)$.

Table 6. Effects of dietary $\beta$-hydroxy- $\beta$-methylbutyrate $(\mathrm{HMB})$ calcium supplementation on biochemical properties of the longissimus dorsi of intra-uterine growth restriction (IUGR) and normal-birth-weight (NBW) piglets

(Mean values with their standard errors)

\begin{tabular}{|c|c|c|c|c|c|c|c|c|}
\hline \multirow[b]{2}{*}{ Parameters } & \multicolumn{2}{|c|}{ CON } & \multicolumn{2}{|c|}{ HMB } & \multirow[b]{2}{*}{ SEM } & \multicolumn{3}{|c|}{$P$} \\
\hline & IUGR & NBW & IUGR & NBW & & BW & $\mathrm{HMB}$ & $\mathrm{BW} \times \mathrm{HMB}$ \\
\hline DNA $(\mu \mathrm{g} / \mathrm{g})$ & 746 & 882 & 859 & 827 & 51 & 0.314 & 0.575 & 0.116 \\
\hline Protein $(\mathrm{mg} / \mathrm{g})$ & 153 & 138 & 138 & 130 & 6 & 0.125 & 0.149 & 0.651 \\
\hline DNA/protein $(\mu \mathrm{g} / \mathrm{mg})$ & 4.90 & $6 \cdot 40$ & $6 \cdot 37$ & 6.55 & 0.52 & 0.125 & 0.136 & 0.223 \\
\hline CK (IU/mg protein) & 4.88 & 4.90 & 5.19 & 5.26 & 0.15 & 0.741 & 0.038 & 0.863 \\
\hline LDH (IU/mg protein) & $1.64^{a, b}$ & $1.51^{\mathrm{b}}$ & $1 \cdot 78^{\mathrm{a}, \mathrm{b}}$ & $2 \cdot 15^{\mathrm{a}}$ & 0.17 & 0.488 & 0.039 & 0.166 \\
\hline
\end{tabular}

CON, control; BW, body weight; CK, creatine kinase; LDH, lactate dehydrogenase.

a,b Mean values within a row with unlike superscript letters were significantly different $(P<0.05)$. 
BW: $P=0.006$

HMB: $P=0.753$

$\mathrm{BW} \times \mathrm{HMB}: P=0.269$

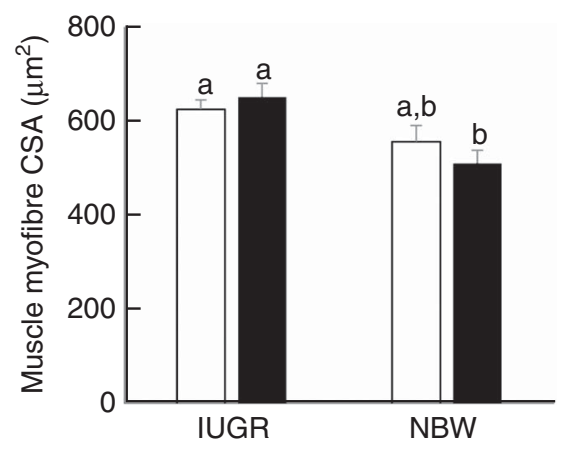

Type I
BW: $P=0.067$

HMB: $P=0.007$

$\mathrm{BW} \times \mathrm{HMB}: P=0.561$

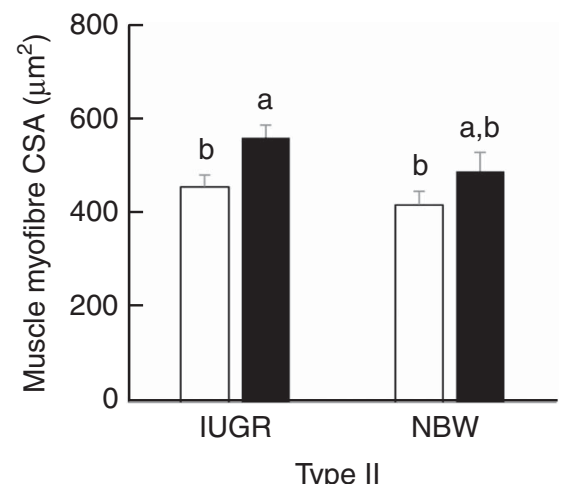

Type II

Fig. 1. Effects of dietary $\beta$-hydroxy- $\beta$-methylbutyrate (HMB) calcium supplementation on the muscle fibre cross-sectional area (CSA) of the longissimus dorsi of intrauterine growth restriction (IUGR) and normal-birth-weight (NBW) piglets. Values are means, with their standard errors represented by vertical bars. ${ }^{a, b}$ Mean values with unlike superscript letters were significantly different $(P<0.05)$. $\square$, Control; $\square$, HMB; BW, body weight.

Table 7. Effects of dietary $\beta$-hydroxy- $\beta$-methylbutyrate (HMB) calcium supplementation on the mRNA level of the myosin heavy-chain (MyHC) isoform and myogenic genes in the longissimus dorsi of intra-uterine growth restriction (IUGR) and normal-birth-weight (NBW) piglets (Mean values with their standard errors)

\begin{tabular}{|c|c|c|c|c|c|c|c|c|}
\hline \multirow[b]{2}{*}{ Genes } & \multicolumn{2}{|c|}{ CON } & \multicolumn{2}{|c|}{$\mathrm{HMB}$} & \multirow[b]{2}{*}{ SEM } & \multicolumn{3}{|c|}{$P$} \\
\hline & IUGR & NBW & IUGR & NBW & & BW & HMB & $\mathrm{BW} \times \mathrm{HMB}$ \\
\hline \multicolumn{9}{|c|}{ MyHC isoform genes } \\
\hline MyHC-I & 1.20 & 1.00 & 1.25 & 1.23 & 0.12 & 0.382 & 0.260 & 0.451 \\
\hline MyHC-Ila & 0.96 & 1.00 & 0.92 & 1.02 & 0.12 & 0.532 & 0.929 & 0.771 \\
\hline$M y H C-\| / x$ & 0.78 & 1.00 & 0.74 & 0.86 & 0.07 & 0.026 & 0.196 & 0.507 \\
\hline$M y H C-I l b$ & $1 \cdot 26^{a, b}$ & $1.00^{b}$ & $1 \cdot 30^{\mathrm{a}, \mathrm{b}}$ & $1.56^{\mathrm{a}}$ & 0.13 & 0.975 & 0.040 & 0.067 \\
\hline \multicolumn{9}{|c|}{ Myogenic genes } \\
\hline MRF-4 & $0.86^{b}$ & $1.00^{a, b}$ & $1 \cdot 14^{\mathrm{a}, \mathrm{b}}$ & $1 \cdot 26^{\mathrm{a}}$ & 0.11 & 0.248 & 0.023 & 0.902 \\
\hline MyoG & 0.95 & 1.00 & 0.91 & 1.11 & 0.10 & 0.222 & 0.743 & 0.464 \\
\hline mTOR & $1 \cdot 12^{\mathrm{b}}$ & $1.00^{\mathrm{b}}$ & $1.77^{\mathrm{a}}$ & $0.96^{b}$ & 0.13 & 0.003 & 0.032 & 0.018 \\
\hline$I G F-1$ & $0.97^{\mathrm{b}}$ & $1.00^{\mathrm{b}}$ & $1.33^{a}$ & $1 \cdot 17^{\mathrm{a}, \mathrm{b}}$ & 0.11 & 0.559 & 0.021 & 0.375 \\
\hline MSTN & 0.81 & 1.00 & 0.93 & 0.99 & 0.12 & 0.332 & 0.663 & 0.597 \\
\hline
\end{tabular}

CON, control; BW, body weight; MRF-4, muscle regulatory factor 4; MyoG, myogenin; mTOR, mammalian target of rapamycin; IGF-1, insulin-like growth factor-1; MSTN, myostatin. a,b Mean values within a row with unlike superscript letters were significantly different $(P<0.05)$.

\section{Protein expression of fast-myosin heavy chain in the} longissimus dorsi of piglets

The data for fast-MyHC protein content in the LD of piglets are presented in Fig. 2. Regardless of BW, the fast-MyHC protein content was significantly higher in the LD of piglets fed HMB-Ca milk than in the LD of piglets fed CON milk $(P<0.05)$. However, dietary HMB-Ca supplementation did not increase fast-MyHC protein content in the LD of IUGR piglets.

\section{Discussion}

The primary aim of the present study was to investigate the influence of the dietary supplementation of HMB-Ca to neonates during the early postnatal period on skeletal muscle growth and development. Piglet performance, to a great extent, is influenced by milk intake, which correlates with maternal milk yield and birth weight ${ }^{(24,25)}$. Therefore, male piglets with similar low and normal $\mathrm{BW}$ were used for IUGR and NBW groups, respectively, in this experiment. We found no significant difference in ADMI between dietary treatments during the entire experimental period, and IUGR piglets showed lower ADMI and ADG compared with those of NBW piglets. It has been shown in previous studies that the poor growth of IUGR piglets during the neonatal period is because of a number of factors, including reduced nutrient intake ${ }^{(26)}$. Interestingly, IUGR piglets fed HMB-Ca milk had a net weight and ADG similar to that of CON-fed NBW piglets in the present study. HMB is a metabolite of leucine, which is used to promote the growth of lean body mass following exercise, and, in particular, it is involved in disease-related muscle wasting ${ }^{(27,28)}$. HMB has been shown to increase muscle protein synthesis through the mTOR signalling pathways while reducing proteolytic processes, which is similar to the response of skeletal muscle to leucine ${ }^{(29)}$. In the current study, HMB-Ca treatment improved the performance of both IUGR and NBW piglets, which is in agreement with the findings of Nissen et $a l .{ }^{(30)}$, who reported that, when fed to sows at $2 \mathrm{~g} / \mathrm{d}$ from day 108 of gestation to day 21 of lactation, HMB-Ca resulted in an increase in the weaning $\mathrm{BW}$ of piglets. In addition, in this 


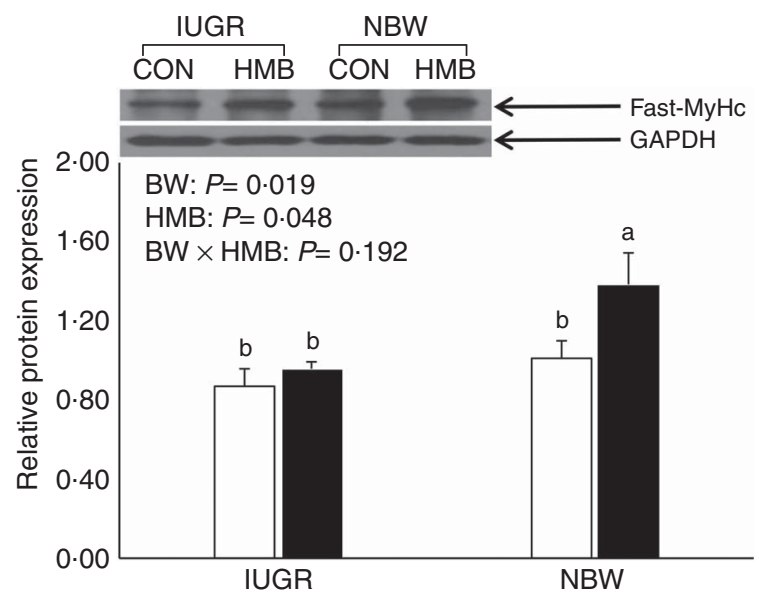

Fig. 2. Effects of dietary $\beta$-hydroxy- $\beta$-methylbutyrate $(\mathrm{HMB})$ calcium supplementation on the fast-myosin heavy-chain (MyHC) protein levels in the longissimus dorsi of intra-uterine growth restriction (IUGR) and normal-birthweight (NBW) piglets. Values are means, with their standard errors represented by vertical bars. ${ }^{a, b}$ Mean values with unlike superscript letters were significantly different $(P<0.05)$. $\square$, Control; $\mathbf{\square}$, HMB; BW, body weight; GAPDH, glyceraldehyde-3-phosphate dehydrogenase

experiment, piglets fed HMB-Ca milk had an increased percentage of skeletal muscle relative to that of CON piglets, which is consistent with the findings of Qiao et $a l^{(31)}$, who found that, when fed to broiler chicks at a dosage of $0 \cdot 1 \%$, HMB-Ca significantly improved breast muscle yield and resulted in less abdominal fat. Similarly, Pimentel et $a l .{ }^{(32)}$ reported that feeding of $\mathrm{HMB}$ at a dosage of $320 \mathrm{mg} / \mathrm{kg} \mathrm{BW}$ to rats induced a significant increase in the weight of the extensor digitorum longus and soleus. Studies have also suggested that a piglet's growth and protein turnover are higher during the neonatal period ${ }^{(13)}$, and the majority of this growth comprises skeletal muscle growth, which represents $30 \%$ of the total body mass ${ }^{(33)}$. These observations indicate that increased performance might be obtained by improving skeletal muscle growth for piglets during the early postnatal period.

The secondary aim of the present study was to explore the mechanisms underlying the direct response of skeletal muscle growth in IUGR and NBW piglets to the dietary HMB-Ca supplementation, which is critical for the development of strategies to improve the growth and health of low-birth-weight neonates. It is well known that insulin and glucose, as well as amino acids, especially leucine, are the main anabolic promoters resulting in protein synthesis in the skeletal muscle of piglets ${ }^{(34)}$, and higher plasma insulin, glucose and amino acid levels can induce greater rates of muscle protein synthesis ${ }^{(35)}$. In the present study, HMB-Ca supplementation significantly increased insulin levels in IUGR and NBW piglets. However, the insulin levels were not significantly different between CON and HMB-fed IUGR piglet groups. A possible reason for this is that IUGR piglets have been shown to exhibit a small degree of insulin resistance during days 2 and 28 postnatal $^{(36,37)}$, leading to higher fasting plasma insulin levels in IUGR piglets. Moreover, dietary HMB supplementation significantly affected the plasma amino acid metabolism of piglets, including increased plasma leucine, BCAA, EAA and NEAA content. It appears that the stimulation of protein synthesis is dependent on signals related to the concentration of extracellular, rather than intramuscular, $\mathrm{EAA}^{(38)}$. Interestingly, we observed that piglets fed HMB-Ca milk had increased levels of HMB in their LD in this study. This effect was also demonstrated in the study by Wheatley et $a l^{(13)}$, who found that, when piglets were infused with HMB at 100 or $400 \mu \mathrm{mol} / \mathrm{kg}$ BW per h for $1 \mathrm{~h}$, an increased HMB level was observed in the LD. This may provide the important evidence to explain why HMB enters the skeletal muscle tissue and promotes protein synthesis. In addition, the plasma urea content was not affected by dietary HMB-Ca treatment in the piglets in this study, providing further evidence that HMB might not promote protein breakdown.

In addition, we found that the LD of piglets supplemented with HMB-Ca milk showed an increase of LDH and CK activities, and had higher type II muscle fibre CSA. Lefaucheur et $a l .{ }^{(10)}$ reported that early postnatal malnutrition reduced the glycolytic capacity and CSA of fast-twitch fibres, leading to a delay in muscle maturation. Previous studies have also indicated that a higher LDH activity, which is a marker for the anaerobic glycolytic fibre, is found in fast glycolytic fibres than in slow oxidative fibres ${ }^{(39)}$, and that LDH activity is related to fibre $\mathrm{CSA}^{(40)}$. Furthermore, fast glycolytic fibres exhibit both a higher specific CK activity (a marker of differentiation in skeletal muscle development) and a greater phosphocreatine content than slow-twitch fibres ${ }^{(41)}$. Therefore, it is possible that the switch to a more anaerobic metabolism in the LD of pigs directly contributes to muscle fibre growth and maturity in response to dietary supplementation with HMB-Ca.

It is also known that muscle development in postnatal piglets is regulated by transcription and growth factors, such as the myogenic differentiation factor $(M y O D)$ family, which comprises four transcriptions factors ( $M y O D$, myogenic factor 5 ( $M y f-5)$, $M y o G$ and $M R F-4$ ), and $I G F-1$ and 2 (IGF-2), which might both stimulate the proliferation of myoblasts ${ }^{(42,43)}$. MyoD and $M y f-5$ are expressed constantly up to the 3rd week after birth, and their expression is followed by a decline in 50-d-old pigs. However, the level of $M R F-4$ level does not show statistically significant differences between different stages of development ${ }^{(44,45)}$. Therefore, we used $M R F-4, M y O G, I G F-1$ and $M S T N$ as the main target genes to evaluate the response of skeletal muscle fibre development to dietary HMB-Ca supplementation. It appears that the transcription factor MRF- 4 regulates the final differentiation of myotubes, and this gene has a 10-fold higher postnatal expression than the other genes of the $M R F$ family ${ }^{(46)}$. In this study, a higher level of MRF-4 mRNA expression was observed in the LD of piglets fed HMB-Ca milk than in the LD of the CON-fed piglets. Furthermore, the feeding of milk supplemented with HMB-Ca significantly increased the $I G F-1$ and $m T O R$ mRNA levels in the LD of piglets, which agrees with the results of Kim et al. ${ }^{(47)}$, who reported a significant $I G F-1$ mRNA increase in the soleus (+33\%) when old, female SpragueDawley rats were administered HMB orally at a dosage of $0.48 \mathrm{~g} / \mathrm{kg}$ per $\mathrm{d}$. Moreover, we found that there was a significant interaction between the effects of $\mathrm{HMB}$ and $\mathrm{BW}$ on $m T O R$ mRNA expression in the LD in this study. It has been suggested that the activation of the mTOR signalling pathway in skeletal muscle is under the control of the arginine family of amino acids and leucine ${ }^{(48)}$. In the current study, an increased leucine content was observed in IUGR piglets fed the HMB-Ca diet than 
in CON-fed NBW piglets, which might also explain the increased expression of $m T O R$ in IUGR pigs fed the HMB-Ca diet. However, at present, it is unclear why dietary HMB-Ca supplementation significantly increased $m T O R$ expression in IUGR piglets but not in NBW piglets. Xu et al. ${ }^{(49)}$ also reported a higher mTOR protein expression in IUGR piglets than in NBW piglets in response to dietary leucine supplementation. Further studies should be conducted in relation to the specific mechanisms of protein synthesis that are mediated by HMB in IUGR piglets.

It appears that marked changes occur in the skeletal muscle growth of piglets during the neonatal period, including rapid myofibril protein accretion ${ }^{(50)}$, changes in MyHC polymorphism, increases in aerobic and glycolytic metabolism and hypertrophy of muscle fibres ${ }^{(51)}$. However, limited studies exist that evaluate the direct impact of dietary HMB-Ca supplementation to piglets on the MyHC isoform mRNA levels of skeletal muscle. In this experiment, $\mathrm{HMB}-\mathrm{Ca}$ treatment significantly increased $M y H C-I I b$ mRNA and fast-MyHC protein levels in the LD of piglets. Research has suggested that high muscularity is positively related to a high abundance of the MyHC-IIb transcript ${ }^{(52)}$, and that from days 7 to 180 after birth the $M y H C-I I b$ mRNA levels show a steadily increasing trend. Moreover, on day 30, MyHC-I and MyHC-IIb mRNA abundances are at their lowest ${ }^{(53)}$. On the basis of previous reports and the data from this experiment on the CK and LDH activities, $M y H C$ $I I b$ and $I G F-1$ mRNA levels, fast-MyHC protein content, the increased muscle growth and maturity in pigs fed HMB-Ca milk could be because of the increased levels of $M y H C-I I b$ mRNA in fast glycolytic fibres, which enhances skeletal muscle fibre differentiation of piglets. However, dietary HMB-Ca supplementation did not increase $M y H C-I I b$ mRNA or fast-MyHC protein expression in IUGR piglets. It has been suggested that newborn piglets exposed to IUGR have accelerated skeletal muscle development with a precocious type II to type I conversion and, as a consequence, an increase in the proportion and maturation of type I fibres ${ }^{(54,55)}$. Similarly, Fahey et al. ${ }^{(56)}$ reported that fibre type shifts in the early neonatal period after maternal dietary restriction in sheep exhibited either a relative increase in type I oxidative fibres or a relative decrease in glycolytic type II fibres. The increased MyHC transition towards type I fibres during the neonatal period for IUGR piglets might result in decreased $M y H C-I I b$ mRNA and fast-MyHC protein levels, and lower LDH activity in the LD in response to dietary HMB-Ca supplementation. The potential molecular mechanisms underlying the different effect on the growth of skeletal muscle in IUGR and NBW piglets fed an HMB diet should also be investigated further.

In conclusion, the findings of the present study suggest that dietary supplementation of HMB-Ca contributes to muscle fibre growth and maturity by accelerating fast-twitch glycolytic fibre development in IUGR and NBW pigs during the early postnatal period. The ability of HMB to stimulate gains in lean mass in young or neonatal animal has been largely ignored, and this study may have important implications for the postnatal skeletal muscle growth of IUGR and NBW piglets during the neonatal period. Future studies are needed to investigate the effects of different levels of HMB-Ca supplementation on lean mass gain in early postnatal piglets.

\section{Acknowledgements}

The authors thank John A. Rathmacher and John C. Fuller, Jr for their immeasurable help in determining the purity of HMB-Ca.

This work was supported by the National Special Research Fund for the Non-Profit Sector (Agriculture) (no. 201203015), the Academy of Kechuang Feed Industry in Sichuan (2013NZ0056), the Research Team of Youth Scientific and Technical Innovation of Sichuan (13CXTD0004) and the Program for Changjiang Scholars and Innovative Research Team in University (IRT13083).

The authors' contributions are as follows: D. Wu designed the study; H. Wan, J. Zhu, G. Su, Y. Liu, L. Hua, C. Wu, R. Zhang, P. Zhou and Y. Shen carried out the study; H. Wan, J. Zhu and G. Su performed the analysis. H. Wan, S. Xu and B. Feng analysed the data; H. Wan wrote the paper and D. Wu, L. Che, Z. Fang, L. Hu and Y. Lin made modifications to the manuscript. The authors declare that there are no conflicts of interest.

\section{References}

1. Columbus DA, Fiorotto ML \& Davis TA (2015) Leucine is a major regulator of muscle protein synthesis in neonates. Amino Acids 47, 259-270.

2. McMillen IC \& Robinson JS (2005) Developmental origins of the metabolic syndrome: prediction, plasticity, and programming. Physiol Rev 85, 571-633.

3. Rehfeldt C \& Kuhn G (2006) Consequences of birth weight for postnatal growth performance and carcass quality in pigs as related to myogenesis. J Anim Sci 84, Suppl., E113-E123.

4. Yates DT, Macko AR, Nearing M, et al. (2012) Developmental programming in response to intrauterine growth restriction impairs myoblast function and skeletal muscle metabolism. J Pregnancy 2012, 631038.

5. Pardo CE, Bérard J, Kreuzer M, et al. (2013) Intrauterine crowding impairs formation and growth of secondary myofibers in pigs. Animal 7, 430-438.

6. Alvarenga AL, Chiarini-Garcia H, Cardeal PC, et al. (2013) Intra-uterine growth retardation affects birthweight and postnatal development in pigs, impairing muscle accretion, duodenal mucosa morphology and carcass traits. Reprod Fertil Dev 25, 387-395.

7. Perruchot MH, Lefaucheur L, Louveau I, et al. (2015) Delayed muscle development in small pig fetuses around birth cannot be rectified by maternal early feed restriction and subsequent overfeeding during gestation. Animal 9, 1-10

8. Vuguin P, Raab E, Liu B, et al. (2004) Hepatic insulin resistance precedes the development of diabetes in a model of intrauterine growth retardation. Diabetes 53, 2617-2622.

9. Davis TA, Burrin DG, Fiorotto ML, et al. (1996) Protein synthesis in skeletal muscle and jejunum is more responsive to feeding in 7- than in 26-day-old pigs. Am J Physiol 270, E802-E809.

10. Lefaucheur L, Ecolan P, Barzic YM, et al. (2003) Early postnatal food intake alters myofiber maturation in pig skeletal muscle. J Nutr 133, 140-147.

11. Boutry C, El-Kadi SW, Suryawan A, et al. (2013) Leucine pulses enhance skeletal muscle protein synthesis during continuous feeding in neonatal pigs. Am J Physiol Endocrinol Metab 305, E620-E631.

12. Anthony JC, Anthony TG, Kimball SR, et al. (2000) Orally administered leucine stimulates protein synthesis in skeletal muscle of postabsorptive rats in association with increased eIF4F formation. J Nutr 130, 139-145. 
13. Wheatley SM, El-Kadi SW, Suryawan A, et al. (2014) Protein synthesis in skeletal muscle of neonatal pigs is enhanced by administration of $\beta$-hydroxy- $\beta$-methylbutyrate. Am J Physiol Endocrinol Metab 306, E91-E99.

14. Moore DT, Ferket PR \& Mozdziak PE (2005) The effect of early nutrition on satellite cell dynamics in the young turkey. Poult Sci $\mathbf{8 4}, 748-756$

15. Gerlinger-Romero F, Guimarães-Ferreira L, Giannocco G, et al. (2011) Chronic supplementation of beta-hydroxy-beta methylbutyrate $(\mathrm{HM} \beta)$ increases the activity of the GH/IGF-I axis and induces hyperinsulinemia in rats. Growth Horm IGF Res 21, 57-62.

16. Kovarik M, Muthny T, Sispera L, et al. (2010) Effects of $\beta$-hydroxy- $\beta$-methylbutyrate treatment in different types of skeletal muscle of intact and septic rats. J Physiol Biochem $\mathbf{6 6}$, 311-319.

17. Han F, Hu L, Xuan Y, et al. (2013) Effects of high nutrient intake on the growth performance, intestinal morphology and immune function of neonatal intra-uterine growthretarded pigs. Br J Nutr 110, 1819-1827.

18. Rehfeldt C, Lefaucheur L, Block J, et al. (2012) Limited and excess protein intake of pregnant gilts differently affects body composition and cellularity of skeletal muscle and subcutaneous adipose tissue of newborn and weanling piglets. Eur J Nutr 51, 151-165.

19. Deshpande P, Jie Z, Subbarayan R, et al. (2013) Development and validation of LC-MS/MS method for the estimation of betahydroxy-beta-methylbutyrate in rat plasma and its application to pharmacokinetic studies. Biomed Chromatogr 27, 142-147.

20. Ehling S \& Reddy TM (2014) Investigation of the presence of $\beta$-hydroxy- $\beta$-methylbutyric acid and $\alpha$-hydroxyisocaproic acid in bovine whole milk and fermented dairy products by a validated liquid chromatography-mass spectrometry method. J Agric Food Chem 62, 1506-1511.

21. Li H, Wan H, Mercier Y, et al. (2014) Changes in plasma amino acid profiles, growth performance and intestinal antioxidant capacity of piglets following increased consumption of methionine as its hydroxy analogue. Br J Nutr 112, 855-867.

22. Guth L \& Samaha FJ (1970) Procedure for the histochemical demonstration of actomyosin ATPase. Exp Neurol 28, 365-367.

23. Wang J, Li X, Yang X, et al. (2011) Maternal dietary protein induces opposite myofiber type transition in Meishan pigs at weaning and finishing stages. Meat Sci 89, 221-227.

24. Skok J, Brus M \& Škorjanc D (2007) Growth of piglets in relation to milk intake and anatomical location of mammary glands. Acta Agric Scand A Anim Sci 57, 129-135.

25. Fix J, Cassady J, Herring W, et al. (2010) Effect of piglet birth weight on body weight, growth, backfat, and longissimus muscle area of commercial market swine. Livest Sci 127, $51-59$.

26. Liu J \& He J (2014) Effects of birth weight and postnatal highfat diet on growth performance, carcass and meat quality in pigs. J Anim Plant Sci 24, 1606-1612.

27. Wilson JM, Lowery RP, Joy JM, et al. (2014) The effects of 12 weeks of beta-hydroxy-beta-methylbutyrate free acid supplementation on muscle mass, strength, and power in resistance-trained individuals: a randomized, double-blind, placebo-controlled study. Eur J Appl Physiol 114, 1217-1227.

28. Eley HL, Russell ST \& Tisdale MJ (2008) Attenuation of depression of muscle protein synthesis induced by lipopolysaccharide, tumor necrosis factor, and angiotensin II by beta-hydroxy-beta-methylbutyrate. Am J Physiol Endocrinol Metab 295, E1409-E1416.

29. Wilkinson DJ, Hossain T, Hill DS, et al. (2013) Effects of leucine and its metabolite beta-hydroxy-beta-methylbutyrate on human skeletal muscle protein metabolism. I Physiol 591, 2911-2923.

30. Nissen S, Faidley TD, Zimmerman DR, et al. (1994) Colostral milk fat percentage and pig performance are enhanced by feeding the leucine metabolite beta-hydroxy-beta-methyl butyrate to sows. J Anim Sci 72, 2331-2337.

31. Qiao X, Zhang HJ, Wu SG, et al. (2013) Effect of beta-hydroxybeta-methylbutyrate calcium on growth, blood parameters, and carcass qualities of broiler chickens. Poult Sci $\mathbf{9 2}$, 753-759.

32. Pimentel GD, Rosa JC, Lira FS, et al. (2011) $\beta$-Hydroxy- $\beta$ methylbutyrate $(\operatorname{HM} \beta)$ supplementation stimulates skeletal muscle hypertrophy in rats via the mTOR pathway. Nutr Metab (Lond) 8, 11.

33. Davis TA \& Fiorotto ML (2009) Regulation of muscle growth in neonates. Curr Opin Clin Nutr Metab Care 12, 78-85.

34. Columbus DA, Fiorotto ML \& Davis TA (2014) Leucine is a major regulator of muscle protein synthesis in neonates. Amino Acids 47, 259-270.

35. Wilson FA, Suryawan A, Gazzaneo MC, et al. (2010) Stimulation of muscle protein synthesis by prolonged parenteral infusion of leucine is dependent on amino acid availability in neonatal pigs. J Nutr 140, 264-270.

36. Gondret F, Père MC, Tacher S, et al. (2013) Spontaneous intrauterine growth restriction modulates the endocrine status and the developmental expression of genes in porcine fetal and neonatal adipose tissue. Gen Comp Endocrinol 194, 208-216.

37. He J, Dong L, Xu W, et al. (2015) Dietary tributyrin supplementation attenuates insulin resistance and abnormal lipid metabolism in suckling piglets with intrauterine growth retardation. PLOS ONE 10, e0136848.

38. Bohé J, Low A, Wolfe RR, et al. (2003) Human muscle protein synthesis is modulated by extracellular, not intramuscular amino acid availability: a dose-response study. J Physiol 552, 315-324.

39. Takekura H \& Yoshioka T (1987) Determination of metabolic profiles on single muscle fibres of different types. J Muscle Res Cell Motil 8, 342-348.

40. Vestergaard M, Oksbjerg N \& Henckel P (2000) Influence of feeding intensity, grazing and finishing feeding on muscle fibre characteristics and meat colour of semitendinosus, longissimus dorsi and supraspinatus muscles of young bulls. Meat Sci 54, 177-185.

41. Conjard A, Peuker H \& Pette D (1998) Energy state and myosin heavy chain isoforms in single fibres of normal and transforming rabbit muscles. Pflugers Arch 436, 962-969.

42. Florini JR, Ewton DZ \& Magri KA (1991) Hormones, growth factors, and myogenic differentiation. Annu Rev Physiol 53, 201-216.

43. Florini JR, Ewton DZ \& Coolican SA (1996) Growth hormone and the insulin-like growth factor system in myogenesis. Endocr Rev 17, 481-517.

44. Caliaro F, Maccatrozzo L, Toniolo L, et al. (2005) Myogenic regulatory factors expressed during postnatal hyperplastic growth in porcine muscles. Basic Appl Myol 15, 55-60.

45. Ropka-Molik K, Eckert R \& Piórkowska K (2011) The expression pattern of myogenic regulatory factors MyoD, Myf6 and Pax7 in postnatal porcine skeletal muscles. Gene Expr Patterns 11, 79-83.

46. Bober E, Lyons GE, Braun T, et al. (1991) The muscle regulatory gene, Myf- 6 , has a biphasic pattern of expression during early mouse development. J Cell Biol 113, 1255-1265.

47. Kim J-S, Park Y-M, Lee S-R, et al. (2012) $\beta$-Hydroxy- $\beta$ methylbutyrate did not enhance high intensity resistance training-induced improvements in myofiber dimensions and myogenic capacity in aged female rats. Mol Cells 34, 439-448. 
48. Meijer AJ \& Dubbelhuis PF (2004) Amino acid signalling and the integration of metabolism. Biochem Biophys Res Commun 313, 397-403.

49. Xu W, Bai K, He J, et al. (2016) Leucine improves growth performance of intrauterine growth retardation piglets by modifying gene and protein expression related to protein synthesis. Nutrition 32, 114-121.

50. Suryawan A, Jeyapalan AS, Orellana RA, et al. (2008) Leucine stimulates protein synthesis in skeletal muscle of neonatal pigs by enhancing mTORC1 activation. Am J Physiol Endocrinol Metab 295, E868-E875.

51. Picard B, Lefaucheur L, Berri C, et al. (2002) Muscle fibre ontogenesis in farm animal species. Reprod Nutr Dev 42, 415-431.

52. Wimmers K, Ngu N, Jennen D, et al. (2008) Relationship between myosin heavy chain isoform expression and muscling in several diverse pig breeds. J Anim Sci 86, 795-803.
53. Men XM, Deng B, Xu ZW, et al. (2013) Age-related changes and nutritional regulation of myosin heavy-chain composition in longissimus dorsi of commercial pigs. Animal 7, 1486-1492.

54. Wank V, Bauer R, Walter B, et al. (2000) Accelerated contractile function and improved fatigue resistance of calf muscles in newborn piglets with IUGR. Am J Physiol Regul Integr Comp Physiol 278, R304-R310.

55. Bauer R, Gedrange $\mathrm{T}$, Bauer $\mathrm{K}$, et al. (2006) Intrauterine growth restriction induces increased capillary density and accelerated type I fiber maturation in newborn pig skeletal muscles. J Perinat Med 34, 235-242.

56. Fahey AJ, Brameld JM, Parr T, et al. (2005) The effect of maternal undernutrition before muscle differentiation on the muscle fiber development of the newborn lamb. J Anim Sci 83, 2564-2571. 